\title{
COMPARISON OF PREOPERATIVE TOPICAL NEPAFENAC (0.1\%), FLURBIPROFEN (0.03\%) AND KETOROLAC (0.4\%) EYE DROPS IN MAINTAINING MYDRIASIS DURING PHACOEMULSIFICATION- A RANDOMISED, DOUBLE-BLIND STUDY
}

\author{
Supriya Mushriff', Kaynat Patel ${ }^{2}$
}

${ }^{1}$ Assistant Professor, Department of Ophthalmology, Index Medical College Hospital and Research Centre, Indore. ${ }^{2}$ Postgraduate Resident, Department of Ophthalmology, Index Medical College Hospital and Research Centre, Indore.

\section{ABSTRACT}

\section{BACKGROUND}

Phacoemulsification with IOL implantation is the current surgical treatment of choice for cataract extraction. Intraoperative manipulation during surgery triggers inflammatory cascade resulting in miosis, pain, inflammation or cystoid macular oedema. Adequate pupillary dilatation and its maintenance is required for proper anterior capsule incision and nucleus delivery and IOL implantation failing which may lead to complications.

Aim- This study compares the effectiveness of prophylactic administration of topical flurbiprofen $0.03 \%$, nepafenac $0.1 \%$ and ketorolac $0.4 \%$ in maintaining mydriasis during phacoemulsification with IOL implantation in the capsular bag.

\section{MATERIALS AND METHODS}

It is a prospective, randomised, double blind study involving 120 eyes undergoing phacoemulsification which were randomly and equally divided into four groups receiving topical nepafenac $0.1 \%$ (Group 1), flurbiprofen 0.03\% (Group 2), ketorolac 0.4\% (Group 3), placebo CMC $0.5 \%$ (Group 4) prior to the surgery. Pupil diameters were recorded at different stages of surgery and the mean value was compared. All the data was analysed with the software SPSS 20.0. Chi square test and ANOVA was used for comparison amongst the four groups.

\section{RESULTS}

Total 120 eyes were included, 50 females and 70 males of mean age $59.458 \pm 8.74$ years. The pupil diameter at the baseline was comparable in all four groups. Significant difference was seen in the pupil diameter in all the groups; however, nepafenac group had the least decrease in the pupil diameter at the end of surgery $(\mathrm{P}=0.009)$.

\section{CONCLUSION}

Topical nepafenac has shown to be a potent inhibitor of miosis during phacoemulsification and also maintained the mydriasis throughout the procedure as compared to topical flurbiprofen, ketorolac and placebo.

\section{KEYWORDS}

NSAID, Phacoemulsification, Prostaglandins, Mydriasis.

HOW TO CITE THIS ARTICLE: Mushriff S, Patel K. Comparison of preoperative topical nepafenac (0.1\%), flurbiprofen (0.03\%) and ketorolac $(0.4 \%)$ eye drops in maintaining mydriasis during phacoemulsification- A randomised, double- blind study. J. Evolution Med. Dent. Sci. 2017;6(40):3189-3192, DOI: $10.14260 / J e m d s / 2017 / 689$

\section{BACKGROUND}

Phacoemulsification with IOL implantation in the bag is the current surgical treatment of choice for cataract extraction. Intra-operative manipulation can trigger the inflammatory cascade resulting in release of prostaglandins which is responsible for miosis, pain, inflammation, conjunctival hyperaemia, cystoid macular oedema.(1)(2)

Maintenance of mydriasis is necessary to facilitate proper incision of the anterior capsule, safe delivery of the nucleus, uncomplicated removal of cortex, and implantation of intraocular lens (IOL). It has been reported that when pupillary diameter $>6 \mathrm{~mm}$ is maintained during surgery, the incidence of posterior capsular rupture, a well-known transoperative complication, is reduced by half.(3)

Financial or Other, Competing Interest: None.

Submission 11-04-2017, Peer Review 04-05-2017,

Acceptance 11-05-2017, Published 18-05-2017.

Corresponding Author:

Dr. Supriya Mushriff,

Assistant Professor,

Department of Ophthalmology,

Index Medical College Hospital and

Research Centre, Indore, Madhya Pradesh.

E-mail: smushriff@gmail.com

DOI: $10.14260 /$ jemds $/ 2017 / 689$
Topical anticholinergic drugs i.e. cyclopentolate and tropicamide along with the adrenergic agonist phenylephrine is routinely used to dilate the pupil.(4) However, subsequent miosis occurs in some patients as soon as the surgeon enters the anterior chamber.

Surgical trauma triggers the release of prostaglandins, prostacyclins, thromboxane $\mathrm{A} 2$, leukotrienes which results in miosis.

Non-steroidal anti-inflammatory drugs (NSAIDs) has reportedly shown to inhibit cyclooxygenase enzyme, hence inhibiting the release of Prostaglandin.(2)(5) NSAID has shown to be effective in treating variety of conditions in which release of prostaglandins play a causative role including surgically included miosis, post-operative inflammation, cystoid macular oedema.(6)(7)(8)

Our study is the first study in Central India that compares the efficacy of three different topical drugs i.e. nepafenac $0.1 \%$, ketorolac $0.5 \%$ and flurbiprofen $0.03 \%$ in maintaining the mydriasis during the phacoemulsification surgery. This study determines the pupillary diameter at three stages of phacoemulsification and determines the percent loss of diameter by the end of surgery. 


\section{MATERIALS AND METHODS}

We conducted the study on 120 eyes of 120 patients diagnosed with cataract. This was a prospective, randomised, double-blinded, comparative study in patients undergoing phacoemulsification with capsular bag IOL implantation at tertiary hospital in central India. The study was conducted from August 2016 - February 2017. All the patients were divided into four groups randomly with each group having 30 patients.

Using $1 \% \alpha$ (for avoiding false positive outcome, as good pupillary dilatation is important for safe surgery), the power calculation determined that at least 18 observations were needed to reach a $95 \%$ power for a mean value of $7 \mathrm{~mm}$ (SD 1.2). $(9,10)$ We have kept the critical value of pupil size as $6 \mathrm{~mm}$ for safe phacoemulsification. To enhance the reliability for our observation and to compensate for dropouts, we have taken a sample size of 30 .

\section{Inclusion Criteria}

1. 40 years of age or older regardless of gender or race.

2. Senile cataract of grade NC $2-3$, NO 2-3 according to the Lens Opacity Classification III (LOCIII).

3. Scheduled for phacoemulsification with capsular bag IOL implantation.

\section{Exclusion Criteria}

1. Ocular inflammation or infectious eye disease.

2. Neurophthalmologic condition affecting the size or the pupil.

3. Allergy and hypersensitivity to preservative and NSAID.

4. Diabetes mellitus with/without retinopathy.

5. Pseudoexfoliation.

6. Use of intraoperative adrenaline.

7. Inadequate mydriasis due to synechiae or iris atrophy.

8. Eye with $<7.00 \mathrm{~mm}$ pupil size at the baseline.

9. Use of tamsulosin or other analogue systemic medication (Floppy Iris Syndrome).

Pre-operatively all the patients underwent thorough ophthalmic examination. Past medical and surgical history and use of concurrent medication was extensively reviewed.

Best corrected visual acuity BCVA using Snellen's chart and slit lamp examination, intraocular pressure with Goldmann Applanation Tonometry and Dilated Fundus examination was done.

A written informed consent for phacoemulsification was taken from the patients who fit the inclusion criteria. All the patients and their attenders were well counselled regarding the study. The declaration of Helsinki was followed during the study. The patients were then distributed into the four groups randomly. Patients received one drop of assigned topical NSAID or placebo ( $0.5 \%$ CMC solution) of four doses at a fifteen-minute interval to the operative eye 1 hour prior to the surgery. The surgeon and the patients were unaware of the type of the test drops given.

To ensure the Double Blindness in the Study the Four Drops used for Study were Wrapped and Labelled as-

- Drop A for group 1.

- $\quad$ Drop B for group 2.

- $\quad$ Drop C for group 3.

- $\quad$ Drop D for group 4.
The paramedic was not aware of the drop being instilled.

Also, the operating surgeon was not informed regarding the group to which the patient belonged to ensure there is no bias-

- Drop A was topical Nepafenac $0.1 \%$.

- Drop B was topical Flurbiprofen $0.03 \%$.

- $\quad$ Drop C was topical Ketorolac $0.4 \%$.

- $\quad$ Drop D was topical CMC 0.5\%.

Eye drop tropicamide $0.8 \%$ with phenylephrine $5 \%$ in four doses at a fifteen-minute interval was also instilled in the operative eye 1 hour prior to the surgery.

All the patients underwent phacoemulsification using the Zeiss machine and multi-piece acrylic IOL implantation in the capsular bag by the same operating surgeon. Phacoemulsification parameters were established prior to the surgery and was same in all the patients. Normal saline without epinephrine was used for corneal irrigation. The corneal wound was left unsutured at the end of surgery. The principal author used the sterile Vernier calliper to measure the horizontal and vertical pupillary diameter. The sterile calliper was placed on the cornea and the measurement in millimetres at following stage of phacoemulsification-

1. Before creating side ports

2. After nuclear emulsification

3. After implantation of foldable IOL and removal of viscoelastic.

All the data was analysed with the software SPSS 20.0. Chi square test and ANOVA was used for comparison amongst the four groups.

\section{RESULTS}

A total of 120 patients were enrolled in the study. 30 patients were randomly divided amongst all the four groups. 50 patients were female and 70 were male. The male: female ratio was 1.4:1. (Figure 1) (Table 1).

All the surgeries went uneventful with no treatment related adverse effect and toxicity was encountered related to topical nepafenac $0.1 \%$, flurbiprofen $0.03 \%$ and ketorolac $0.4 \%$.

The age of our patients ranged from $40-80$ years. The mean age of our patients was $59.458 \pm 8.74$ years. The mean age of patients in Nepafenac group was $61.8 \pm 9.09$ years, $61.33 \pm 9.66$ years in Flurbiprofen group, $57.9 \pm 8.91$ years in Ketorolac group and $60.7 \pm 7.15$ years in the Placebo group.

This difference was statistically insignificant $(\mathrm{P}=0.187)$.

The ANOVA test revealed a statistically insignificant difference of mean pupil size measured before surgery between the Nepafenac and Flurbiprofen group, Nepafenac and Ketorolac Group, Nepafenac and Placebo group, Flurbiprofen and Ketorolac group, Flurbiprofen and Placebo, Ketorolac and Placebo group. (P - value $\geq 0.05$ ).

The mean diameter of pupil at end of Phaco was $8.15 \pm$ $0.68 \mathrm{~mm}$ in Nepafenac group, $7.53 \pm 0.87 \mathrm{~mm}$ in Flurbiprofen group, $8.08 \pm 0.70 \mathrm{~mm}$ in Ketorolac group and $7.90 \pm 0.64 \mathrm{~mm}$ in Placebo group. (P-value $\leq 0.05$ ).

Meanwhile the mean diameter of pupil at the end of surgery was $7.88 \pm 0.76 \mathrm{~mm}$ in Nepafenac group, $7.15 \pm 1.00$ $\mathrm{mm}$ in Flurbiprofen group, $7.33 \pm 0.68 \mathrm{~mm}$ in Ketorolac group and 7.43 $\pm 0.66 \mathrm{~mm}$ in Placebo group. (Table 2). (Figure 2).

The mean decrease in pupil size from baseline to end of Phaco was $0.25 \pm 0.28 \mathrm{~mm}$ (range $0.00-1.00 \mathrm{~mm}$ ) in 
Nepafenac group , $0.55 \pm 0.46 \mathrm{~mm}$ (range $0.00-1.50 \mathrm{~mm}$ ) in Flurbiprofen group, $0.35 \pm 0.23 \mathrm{~mm}$ (range $0.00-0.050 \mathrm{~mm}$ ) in Ketorolac group, and $0.51 \pm 0.33 \mathrm{~mm}$ (range $0.00-1.0 \mathrm{~mm}$ ) in placebo group $(\mathrm{P}-$ value $<0.05)$ (Figure 3$)$.

Meanwhile; the mean decrease in pupil size from baseline to the end of surgery was $0.55 \pm 0.51 \mathrm{~mm}$ (range $0.00-1.50$ $\mathrm{mm}$ ) in Nepafenac group $0.93 \pm 0.62 \mathrm{~mm}$ (Range $0.00-2.00$ $\mathrm{mm}$ ) in Flurbiprofen group $0.75 \pm 0.28 \mathrm{~mm}$ (range 0.5-1.5 $\mathrm{mm}$ ) in Ketorolac group and $1.01 \pm 0.48 \mathrm{~mm}$ (Range 0.5-2.5 $\mathrm{mm}$ ) in placebo group $(\mathrm{P} \leq 0.05)$ (Figure 3$)$.

\begin{tabular}{|c|c|c|c|c|c|}
\hline & $\begin{array}{c}\text { Nepa } \\
\text { fenac }\end{array}$ & $\begin{array}{c}\text { Flurbi } \\
\text { profen }\end{array}$ & Ketorolac & Placebo & Total \\
\hline Male & 15 & 23 & 12 & 20 & 70 \\
\hline Female & 15 & 7 & 18 & 10 & 50 \\
\hline
\end{tabular}

Table 1. Gender Distribution among Different Drug Groups

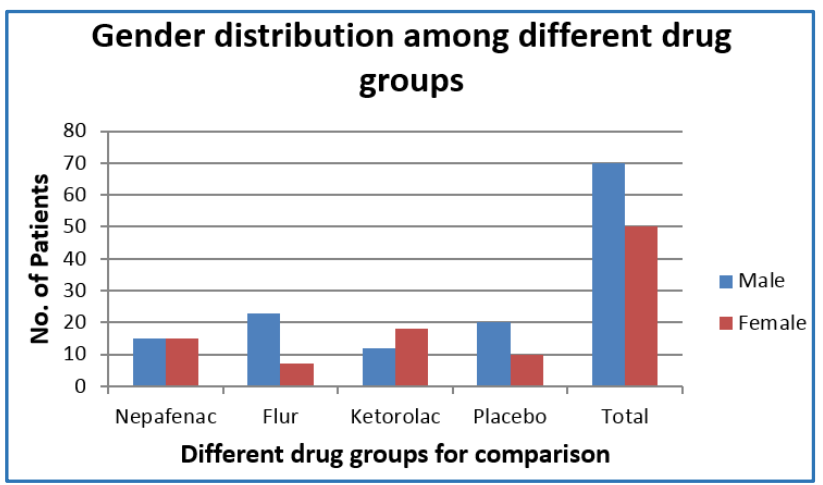

Figure 1. Gender Distribution among Different Drug Groups

\begin{tabular}{|c|c|c|c|c|}
\hline $\begin{array}{l}\text { Pupil Size } \\
\text { (in mm) }\end{array}$ & $\begin{array}{c}\text { Nepafenac } \\
(\mathrm{n}=30)\end{array}$ & $\begin{array}{c}\text { Flurbiprofen } \\
(\mathrm{n}=\mathbf{3 0})\end{array}$ & $\begin{array}{c}\text { Ketorolac } \\
(\mathrm{n}=\mathbf{3 0})\end{array}$ & $\begin{array}{l}\text { Placebo } \\
(n=30)\end{array}$ \\
\hline Baseline & $\begin{array}{c}8.40 \pm \\
0.72\end{array}$ & $\begin{array}{c}8.08 \pm \\
0.75\end{array}$ & $\begin{array}{c}8.08 \pm \\
0.68\end{array}$ & $\begin{array}{l}8.41 \pm \\
0.55\end{array}$ \\
\hline $\begin{array}{l}\text { End of } \\
\text { PHACO }\end{array}$ & $\begin{array}{c}8.15 \pm \\
0.68\end{array}$ & $\begin{array}{c}7.53 \pm \\
0.87\end{array}$ & $\begin{array}{c}8.08 \pm \\
0.70\end{array}$ & $\begin{array}{c}7.90 \pm \\
0.64\end{array}$ \\
\hline $\begin{array}{c}\text { End of } \\
\text { Surgery }\end{array}$ & $\begin{array}{c}7.88 \pm \\
0.76\end{array}$ & $\begin{array}{c}7.15 \pm \\
1.00 \\
\end{array}$ & $\begin{array}{c}7.33 \pm \\
0.68 \\
\end{array}$ & $\begin{array}{c}7.43 \pm \\
0.66\end{array}$ \\
\hline $\begin{array}{c}\text { Mean } \\
\text { Decrease } \\
\text { @ PHACO }\end{array}$ & $\begin{array}{c}0.25 \pm \\
0.28\end{array}$ & $\begin{array}{c}0.55 \pm \\
0.46\end{array}$ & $\begin{array}{c}0.35 \pm \\
0.23\end{array}$ & $\begin{array}{c}0.51 \pm \\
0.31\end{array}$ \\
\hline $\begin{array}{c}\text { Mean } \\
\text { Decrease } \\
\text { @ Surgery }\end{array}$ & $\begin{array}{c}0.55 \pm \\
0.51\end{array}$ & $\begin{array}{c}0.93 \pm \\
0.62\end{array}$ & $\begin{array}{c}0.75 \pm \\
0.28\end{array}$ & $\begin{array}{c}1.01 \pm \\
0.48\end{array}$ \\
\hline
\end{tabular}

Table 2. Comparison of Mean \pm Standard Deviation of Pupil Size (IN MM) at Different Stages of Surgery $(n=120)$

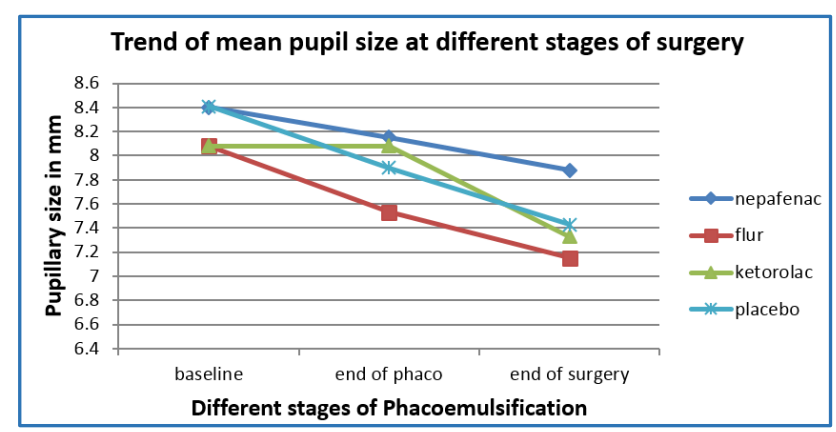

Figure 2. Trend of Mean Pupil Size at Different Steps of Surgery
Variation of Pupillary size in different groups at the end of Phacoemulsification

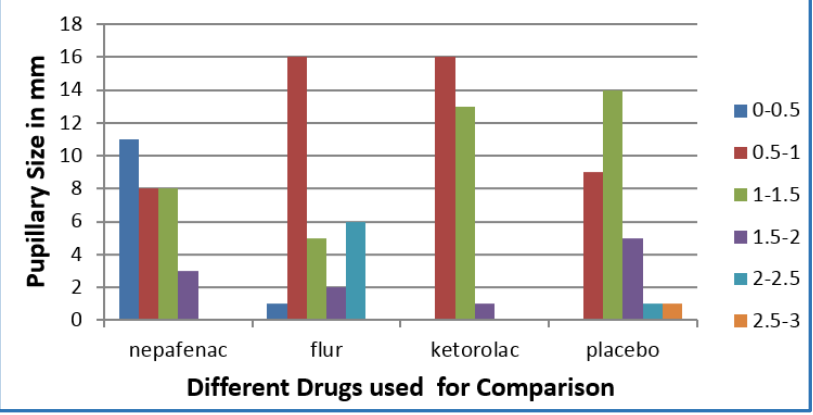

Figure 3. Decrease in Pupil Size from Baseline to End of Phaco

After we summarised whole data, by ANOVA testing, we found an insignificant relationship between different drug groups at the start of surgery, i.e. $\mathrm{P}$-value $>0.05$. $(\mathrm{P}=0.08)$.

But we found a significant relationship between different drug groups after phacoemulsification i.e. P-value $<0.05$ $(\mathrm{P}$-value $=0.01)$ and at the end of Surgery P-value $<0.05$ $(P=0.004)$ which shows validity of our results.

\section{DISCUSSION}

During phacoemulsification, ocular trauma like incision, iris manipulation, prolonged irrigation, results in release of prostaglandins which play a major role in causing inflammation, pain, miosis, increased IOP and pseudophakic CME. Intraoperative miosis acts as a hurdle in the operative procedure. Many studies have demonstrated that NSAIDs are effective drugs in maintaining the intraoperative mydriasis(5) and preventing post-operative ocular inflammation CME.(11)

Our current studies compare all the topically used NSAID and their relative potency in inhibiting the intraoperative mydriasis at different stages of surgery. Our study demonstrated that Nepafenac $0.1 \%$ which is a new generation NSAID pro-drug showed consistent inhibition of miosis as well as maintaining greater pupillary diameter during the different stages of surgery, as compared to other NSAID and placebo. Shaikh and colleagues analysed the antimiotic effect of prednisolone compared with flurbiprofen. There were no statistically significant differences between the two drugs as in their study they used intracameral epinephrine 1:106 solution, a potent direct-acting mydriatic agent, in every case in our study we haven't used intracameral epinephrine.(12)

Gimbel et al showed that flurbiprofen $0.03 \%$ and indomethacin $1 \%$ have equal efficacy in maintaining pupillary mydriasis during cataract surgery.[13]

Abdel proved that topical flurbiprofen $0.03 \%$ and dexamethasone acetate $0.1 \%$ were both effective in maintaining trans-operative pupillary dilatation during cataract surgery and flurbiprofen had better and more prolonged effect.[14]

In our study, Nepafenac $0.1 \%$ showed maximum ability in maintaining the pupillary diameter throughout the surgery followed by ketorolac $0.4 \%$, then flurbiprofen $0.03 \%$ and lastly placebo.

Similarly, Cervantes-Coste et al from Mexico had reported that the pre-operative use of nepafenac $0.1 \%$ was helpful in retaining mydriasis during phacoemulsification surgery. The 
reduction in pupil diameter from beginning to the end of surgery was $1.59 \pm 0.94 \mathrm{~mm}$ in control group vs. $0.78 \pm 0.56$ $\mathrm{mm}$ in nepafenac group. According to our study, the decrease of pupillary diameter was $0.55 \pm 0.51$ the least as compared to other tested topical NSAID.(15)

Solomon in USA showed that ketorolac $0.05 \%$ provided a better mydriatic effect as compared to topical flurbiprofen $0.03 \% .{ }^{(16)}$

Similar observation was made in our study where the mean decrease in the pupillary diameter at the end of surgery in topical flurbiprofen $(0.03 \%)$ group was less than the topical ketorolac $(0.4 \%)$ group.

We did not find any other study which compared the efficacy of topical nepafenac $0.1 \%$ topical ketorolac $0.4 \%$, topical flurbiprofen $0.03 \%$ and placebo $(0.5 \%$ CMC) in maintaining the pupillary dilatation in phacoemulsification and any reference to it in a computerised search at PubMed. Additional studies are yet to be performed to confirm the findings of our study.

\section{CONCLUSION}

In the end, we want to conclude that for an uneventful phacoemulsification surgery, adequate intraoperative dilatation is a must. To achieve this, pre-operative NSAIDs are recommended in addition to mydriatics.

In our study, we compared 3 NSAIDS i.e. Nepafenac, Ketorolac, Flurbiprofen for their potency in maintaining intra-operative dilatation. We found Nepafenac is potent among other NSAIDS in the study.

We recommend the use of preoperative Nepafenac in addition to mydriatics for effective intra-operative pupillary dilatation and thus achieving the goal of uneventful Phacoemulsification surgery.

\section{REFERENCES}

[1] Goodman DF, Stark WJ, Gottsch JD. Complication of cataract extraction with intraocular lens implantation. Ophthalmic Surg 1989;20(2):132-40.

[2] Guzek JP, Holm M, Cotter JB, et al. Risk factors for intraoperative complications in 1000 extracapsular cataract cases. Opthalmology 1987;94(5):461-6.

[3] Podos SM. Prostaglandins, nonsteroidal antiinflammatory agents and eye disease. Trans Am Ophthalmol Soc 1976;74:637-60.

[4] Papa V, Russo S, Russo P, et al. Naproxen Study Group. Topical naproxen sodium for inhibition of miosis during cataract surgery. Prospective, randomized clinical trials. Eye (Lond) 2002;16(3):292-6.
[5] Flach AJ. Cyclo-oxygenase inhibitors in ophthalmology. Surv Ophthalmol 1992;36(4):259-84.

[6] Nichols J, Snyder RW. Topical nonsteroidal antiinflammatory agents in ophthalmology. Curr Opin Ophthalmol 1998;9(4):40-4.

[7] Schalnus R. Topical nonsteroidal anti-inflammatory therapy in ophthalmology. Ophthalmologica 2003;217(2):89-98.

[8] Kim A, Stark WJ. Are topical NSAIDs needed for routine cataract surgery? Am J Ophthalmol 2008;146(4):483-5.

[9] Lam PT, Poon BT, Wu WK, et al. Randomized clinical trial of the efficacy and safety of tropicamide and phenylephrine in preoperative mydriasis for phacoemulsification. Clin Ophthalmol 2003;31(1):52-6.

[10] Narváez J, Kronberg BP, Park H, et al. Pupil dilation using a standard cataract surgery regimen alone or with atropine $1.0 \%$ pretreatment: Prospective comparative evaluation. J Cataract Refract Surg 2010;36(4):563-7.

[11] Drolsum L, Davanger M, Haaskjold E. Risk factors for an inflammatory response after extracapsular cataract extraction and posterior chamber IOL. Acta Ophthalmol (Copenh) 1994;72(1):21-6.

[12] Shaikh MY, Mars JS, Heaven CJ. Prednisolone and flurbiprofen drops to maintain mydriasis during phacoemulsification cataract surgery. J Cataract Refract Surg 2003;29(12):2372-7.

[13] Gimbel H, Van Westenbrugge J, Cheetham JK, et al. Intraocular availability and pupillary effect of flurbiprofen and indomethacin during cataract surgery. J Cataract Refract Surg 1996;22(4):474-9.

[14] Mahdy MA. Effect of flurbiprofen and dexamethasone acetate in prevention of surgically induced miosis during cataract surgery. J Am Sci 2011;7(11):474-8.

[15] Cervantes-Coste G, Sánchez-Castro YG, Orozco-Carroll $\mathrm{M}$, et al. Inhibition of surgically induced miosis and prevention of postoperative macular edema with nepafenac. Clin Ophthalmol 2009;3:219-26.

[16] Solomon KD, Turkalj JW, Whiteside SB, et al. Topical $0.5 \%$ ketorolac vs. $003 \%$ flurbiprofen for inhibition of miosis during cataract surgery. Arch Ophthalmol 1997;115(9):1119-22. 